\title{
ICT Usage in Industrial Symbiosis: Problem Identification and Study Design
}

\author{
Linda Kosmol \\ Technische Universität Dresden \\ Chair of Business Informatics, esp. Systems \\ Engineering \\ 01062 Dresden, Germany \\ linda.kosmol@tu-dresden.de
}

\author{
Christian Leyh \\ Technische Universität Dresden \\ Chair of Business Informatics, esp. IS in \\ Manufacturing and Commerce \\ 01062 Dresden, Germany \\ christian.leyh@tu-dresden.de
}

\begin{abstract}
Industrial symbiosis is a favored approach to balancing industry's economic growth and its environmental impact on a regional scale. Although the scientific literature reports a multitude of examples of industrial symbiosis around the world, this approach and its related concepts are not considered to be widespread in practice, due to various barriers. Information and management barriers are seen as significant obstacles to industrial symbiosis; however, they have not been adequately investigated yet. Empirical research capturing the perception of industrial actors is lacking. This applies especially to information and communication technology designed to reduce informational barriers. Therefore, in this research-inprogress paper, we will first examine these aspects by discussing related publications. In the second step, we develop a study design involving an online questionnaire to examine the extent of managerial and informational barriers that prevent industrial symbiosis as well as the perception of corresponding technological support.
\end{abstract}

\section{INTRODUCTION}

The term "sustainability" has become omnipresent and a central issue in discussions on industrial development. In this regard, one approach to sustainable industrial development that is attracting more and more research attention is industrial symbiosis. Industrial symbiosis aims to balance industrial activities and their impact on the environment. It involves regional, cross-sectoral, and cross-company cooperation to increase resource efficiency and to ecologically and economically benefit the parties involved [1], [2]. As a result, this approach can create so-called 'industrial ecosystems' or 'eco-industrial parks' from conventional industrial systems or parks, in which local industries adopt symbiotic behavior and commit to sustainable development policies [3], [4].

Nevertheless, reports show that industrial symbiosis is not widely implemented in practice, due to technical/physical, financial, economic, regulatory, social, informational, and managerial barriers [5], [6]. According to [7], less than $0.1 \%$ of 26 million active enterprises in Europe are engaged in industrial symbiosis. In particular, managerial (e.g., limited commitment) and informational (e.g., lack of information/knowledge sharing) barriers are regarded as significant obstacles to industrial symbiosis [5]-[10], since they must be overcome for symbiotic opportunities to be identified. If these barriers are not addressed, subsequent processes - such as feasibility studies of identified opportunities - cannot be carried out and other related barriers (such as technical or financial issues) cannot be identified.

Different examples of industrial symbiosis around the world have been described in the scientific literature [11], [12]. These examples contribute to sustainable development in economic (e.g., reduced waste disposal and input costs), environmental (e.g., reduction waste production and resource use), and social (e.g., community awareness) terms. However, at this point, industrial symbiosis research needs more empirical and quantitative studies, which are currently lacking (as stated by [13]). In recent years, some surveys on industrial symbiosis activities and barriers have been conducted, both to examine the interest in and maturity of industrial symbiosis in a specific region and to capture the perception of barriers to adopting symbiotic behavior (see Table I). The surveys usually address companies (general or environmental managers) or policymakers but rarely the managers of industrial parks, despite the wide recognition of their potential role as facilitators [14], [15].

TABLE I.

INDUSTRIAL SYMBIOSIS SURVEYS ON INDUSTRIAL SYMBIOSIS

\begin{tabular}{|l|l|l|l|l|}
\hline Year & Article & Region & Focus & $\begin{array}{l}\text { Sample } \\
2\end{array}$ \\
\hline 2016 & $\begin{array}{l}{[16],} \\
{[17]}\end{array}$ & Philippines & Barrier interdependencies (10) & 10 \\
\hline \multirow{2}{*}{2017} & {$[18]$} & Brazil & Social barriers (4) & 29 \\
\cline { 2 - 5 } & {$[14]$} & Europe & Symbiosis activity, barriers (5) & 92 \\
\cline { 2 - 5 } & {$[15]$} & Europe & $\begin{array}{l}\text { Symbiosis activity, barriers } \\
(10)\end{array}$ & n/a \\
\hline \multirow{2}{*}{2018} & {$[19]$} & Slovenia & Symbiosis activity (-) & 50 \\
\cline { 2 - 5 } & {$[20]$} & Sweden & $\begin{array}{l}\text { Symbiosis activity, maturity, } \\
\text { barriers (4) }\end{array}$ & $20(50)$ \\
\cline { 2 - 5 } & {$[21]$} & Spain & Symbiosis activity, barriers (9) & 95 \\
\hline \multirow{2}{*}{2019} & {$[22]$} & Europe & $\begin{array}{l}\text { Symbiosis activity, impacts, } \\
\text { barriers (12) }\end{array}$ & $22(25)$ \\
\hline
\end{tabular}

\footnotetext{
${ }^{2}$ No. in brackets $=$ No. of follow-up interviews
}

This work was not supported by any organization.

${ }^{1}$ No. in brackets $=$ No. of barrier categories 
Financial/economic and regulatory barriers are considered the largest barriers by many study participants. In terms of informational and managerial barriers, views are mixed, with large variation in perceived relevance. These differences can be caused by region and context, but also by the different barrier categorizations proposed in the different studies. Informational, managerial, and social aspects are not clearly separated with regard to how barrier categories are assigned. Informational barriers in particular are often linked with social factors such as trust, cooperation, and community. Although a cause-effect relationship may exist (according to [14] and [15], managerial barriers are a causal factor and informational barriers are an effect factor), the present inconsistency in barrier categorization and the lack of a uniform allocation of the underlying aspects make it difficult to compare the studies, reducing their clarity and validity.

Only [19] and [21] considered informational barriers separate from social aspects, albeit exclusively with reference to information systems. The survey of [21] reveals that some companies consider inadequate information management systems to be a barrier. The survey of [19] shows that 49 out of 50 respondents would use an online platform to search for potential partners if one was available. However, in both studies, no further information is given regarding the information system/online platform (information types, functionality, access structure, users, etc.). Therefore, the extent of informational barriers and their cause remain unknown.

A similar lack of empirical foundation can be seen in the efforts to support industrial symbiosis with information and communication technology (ICT), as a way to mitigate informational issues. These tools appear to be primarily research-driven, and the extent to which they are known, used, and judged useful by companies remains unclear [8], [23]. Therefore, we decided to set up a long-term research project to address this research gap. In our opinion, research must further explore the readiness of companies and managers in industrial parks to practice industrial symbiosis, as well as the opinions on informational issues and ICT support. An investigation into informational aspects regarding information availability, confidentiality, and relevance, as well as on the perception of ICT support, will especially contribute to understanding and uncovering gaps between research efforts and practice. Therefore, the aim of this research-in-progress paper - the first step of our research project - is to identify and clarify the necessary aspects of informational and managerial barriers and of ICT support for industrial symbiosis, in terms of problem identification. In addition, we will present our initial study design (an online questionnaire) and outline the next steps of our ongoing research.

This paper is structured as follows. Section II presents the theoretical background on industrial symbiosis and its barriers in terms of problem identification. Then, Section III describes our study design. Finally, Section IV concludes the paper with a discussion and future steps.

\section{THEORETICAL BACKGROUND AND PROBLEM IDENTIFICATION}

\section{A. Business Models in Industrial Symbiosis}

Originally, the term 'industrial symbiosis' covered the physical exchange of material, energy, water, and by-products between geographically close companies in order to achieve economic and environmental advantages [1]. Today, the term encompasses all business models of inter-firm exchange or sharing of under-utilized resources like material, energy, logistics, capacities, space, expertise, and knowledge [2]. The business models (synergies) are therefore either exchangebased or sharing-based and are commonly divided into three categories [24], [25]:

- By-product exchange and reuse

- Utility and infrastructure sharing

- Service sharing

By-product exchange refers to one company's residual outputs (e.g., waste and by-products) being used as another company's inputs (e.g., water, material, waste heat). Here, the principle of circular economy is followed. Utility and infrastructure sharing refers to joint use and/or operation of technical infrastructure and decentralized plants, such as a combined heat and power plant, water treatment plant, district heating grid, etc. Service sharing refers to cross-company management or joint provision of common services, (e.g., joint disposal/procurement, logistics and warehousing, staff training, knowledge exchange).

Depending on the business model and the role of the company (e.g., supplier or consumer), various economic and ecological advantages can arise for the parties involved and for the corresponding region: reduced resource consumption and waste generation, eco-innovation, revenues from residues and by-products, less raw material and disposal costs, development of new business and market opportunities, etc. [26].

The development mechanisms of industrial symbiosis can be divided into three categories-self-organized, facilitated, and planned/designed - with the degree of the involvement of coordinating/mediating third parties (e.g., research institutes, governmental agencies, park management) increasing [27]. Intermediaries are regarded as vital to supporting contact initiation, to collecting necessary information and knowledge, and to facilitating their exchange between companies [28]. Park managers are considered to be the best candidates to provide this social and informational infrastructure to the companies in an industrial park [5].

\section{B. Informational and Managerial Barriers to Industrial Symbiosis}

\section{1) Informational Barriers}

The availability of information and knowledge, as well as the willingness to share them with others, is essential to identifying and evaluating synergy opportunities for industrial symbiosis. For example, in the case of a potential 
by-product exchange, this would include information on the incoming and outgoing resource flows of companies, as well as knowledge of relevant compatibility criteria and technical expertise to implement synergies. However, lack of trust, confidentiality issues, and motivational issues may lead to an unwillingness to share necessary information and knowledge [5], [28], [29]. Lack of internal information, lack of contacts and relationships with whom to share information and knowledge, communication issues, and difficulty to share knowledge limit available information and knowledge sources [6], [8], [30]. Confidentiality issues in particular have not been investigated in the context of industrial symbiosis.

Since we want to determine to what extent informational barriers exist, we want to keep them as separate as possible from social aspects, such as trust and relationships. Therefore, we consider the following issues to be informational barriers to industrial symbiosis:

- Unawareness of principles and benefits of industrial symbiosis

- Lack of available information and knowledge

- Unwillingness to and difficulty of sharing information and knowledge

- Non-transparency and inefficiency of the information and knowledge exchange

- Lack of information-sharing mechanisms and infrastructure

ICT support is considered to be promising in alleviating informational barriers and providing a space for interaction and exchange between companies [9], [10]. Generally, these tools (developed or conceptualized) are online repositories (e.g., ISData) and platforms (e.g., eSymbiosis) that provide various functions for disseminating and sharing information and knowledge as well as for facilitating byproduct exchanges via waste market functions and automatic matching engines.

However, industrial symbiosis ICT tools face various barriers [31], [32]. Currently, these ICT tools are not provided with enough data and information for them to be used effectively. This may be caused by lack of willingness to use the tools, confidentiality issues, manual effort required for data entry, lack of knowledge of the existence of such tools, and access restrictions - thus leading to a low number of potential users. Social networking approaches [33], [34] have increasingly addressed criticisms of early tools for not taking sufficient account of the social context [8]. In addition, many tools limit their functionality to the early stages of industrial symbiosis (synergy identification and assessment) [8], [10]. Moreover, many tools are not easily/publicly accessible, not operational, or still in the concept or development stages [8], [10]. Hardly any statements can be found on the operational tools as to the context in and extent to which they are used, how and by whom, and which specific functions they provide to (potential) users. Therefore, it is difficult to assess how useful current ICT support is to industrial symbiosis.

\section{2) Managerial Barriers}

In order to gather and share information and knowledge, there must be a willingness to commit to sustainable business models; to participate in workshops; and to provide time, personnel, and (likely) financial resources. Synergy identification and implementation do not only deal with resources, they also require resources. Without commitment to incorporating the concept of industrial symbiosis into a holistic strategy and business processes of participating companies, the discovered potential synergies may remain unused [8]. Since the potential benefits are unknown and difficult to predict at first, and since coordination and the exchange of information and knowledge are time-consuming, this commitment and willingness must continue beyond initial meetings and workshops. Therefore, we consider the following (organizational) aspects as managerial barriers:

- Lack of commitment to sustainable business and to the community/network

- Lack of management support

- Unwillingness to collaborate and communicate

The attitude of the company and park management not only influences the extent of informational barriers but can also determine how - and if - ICT tools are used for industrial symbiosis.

\section{RESEARCH APPROACH}

\section{A. Overall Research Approach}

In our research project, we pursue the design of an ICT tool (IT artifact) to mitigate and overcome informational and managerial issues in industrial symbiosis. Therefore, we follow the design science paradigm [33]. The steps for design science in information systems research are shown in Fig. 1.

Currently, we are in the first stages of our long-term research project. We initiated our research by identifying the problem (managerial and informational barriers) and solution space (ICT) in industrial symbiosis through a comprehensive literature review and discussions with industrial partners. As described in Section II, managerial and informational barriers still persist, and ICT solutions encounter a number of problems. Furthermore, design guidelines and best practices for ICT solutions that enable/support industrial symbiosis are lacking [31].

Like other researchers, we believe that ICT tools, particularly digital platforms, can contribute to overcoming managerial and informational barriers, but only if the design is tailored to the needs, circumstances, and restrictions of the intended users. Capturing these aspects requires capturing the general attitude of management towards industrial symbiosis along with the associated exchange of information and knowledge and the corresponding ICT. To this end, we will conduct a survey with the relevant industrial players in industrial symbiosis in industrial parks. This problemcentered approach underlines the relevance of the topic and clarifies the problems addressed in our research project. 
Based on the answers and the information obtained in subsequent interviews, we aim to deduce where an ICT tool could and should be applied, and what it could achieve in terms of enabling industrial symbiosis. By conducting empirically-grounded problem identification and aligning it with the existing solution space, we aim to reconfirm our research gap — thus thoroughly justifying our project — and to ensure that the ICT tool is designed in such a way that it can be embedded in existing strategies and processes to address this important issue [23].

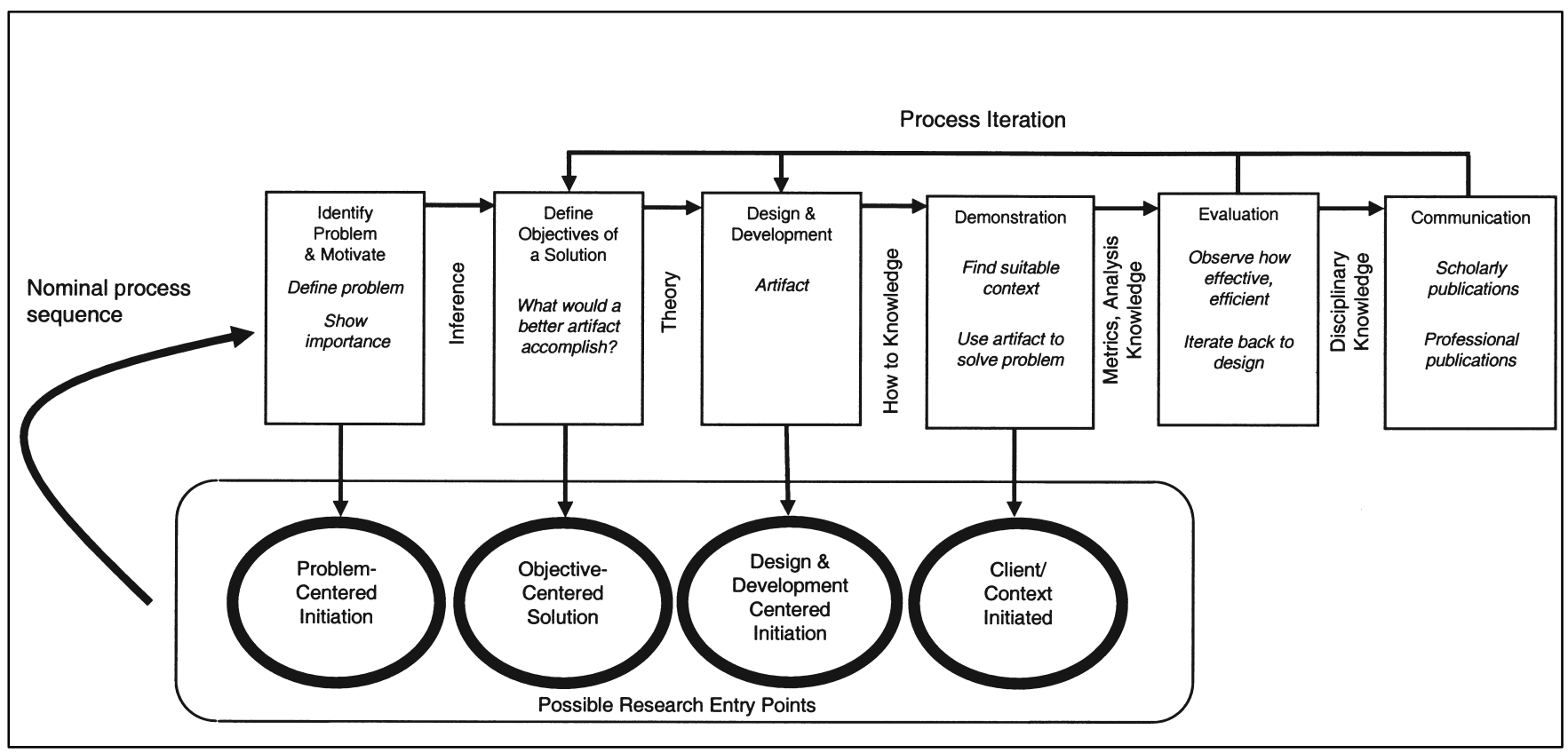

Fig. 1 Design Science Research Methodology [33]

\section{B. Proposal of Study Design - Online Questionnaire}

To address the identified problems/barriers and to investigate them in more detail, thus filling this gap in the literature, we set up a study design based on an online questionnaire. The aim of this approach is to reach a large number of companies and to gather various opinions and perceptions of managerial, informational, and ICT-related aspects in the context of industrial symbiosis. The questionnaire will be provided in German for companies in Germany, Austria, and Switzerland and in English for other European companies. It will primarily be sent to companies in industrial parks and to park managers, as these companies and park management are predestined for industrial symbiosis. We aim to gain insights into the (estimated) willingness and ability of companies to cooperate in industrial symbiosis and into the willingness and ability of park management to act as a facilitator. The questionnaire is composed of four sections:

\section{1) General Data - Participant Characterization}

In order to accurately analyze the answers of the participants, the participants themselves must be sufficiently characterized. Therefore, the general data section includes, for example, the following information:
- Size of company/industrial park (number of employees/companies), which indicates the human resources available and the number of potential synergy partners

- Length of stay at site (in years), which may influence the number of established contacts and (business) relationships

- Certification in energy (ISO 50001) and/or environmental management (ISO 14001/EMAS) and acknowledgement of the importance of energy and material consumption and waste, which indicates the relevancy of sustainability issues.

The characteristics of enterprises and the comparisons between them may reveal fundamental differences in readiness as well as in business and information attitudes towards industrial symbiosis, from which different conclusions can be drawn (e.g., requirement profiles).

\section{2) Managerial Aspects - Current Practice, Readiness, and Potentials}

The extent of management-related barriers is reflected in the current practices and the readiness to adopt industrial symbiosis practices and business models. Therefore, the first block will question the current practice, including the type of the business model and the role of the company. This block 
also examines awareness of the concept of industrial symbiosis regardless of specific terms.

Subsequently, the survey participants will be asked to assess the readiness, interest, and potential opportunities of the company/companies to practice industrial symbiosis. Questions related to readiness indicate a company's ability to collaborate at the company level, while questions related to potential assess the company's ability to collaborate at the network level (by questioning the perceptions of other companies in the industrial park). To measure readiness and potential, we use the proposed readiness areas of [34]. These areas involve the business models of industrial symbiosis (e.g., readiness for by-product exchange) and the company's strategic orientation towards industrial symbiosis (e.g., readiness to pursue common goals or to provide time and personnel for industrial symbiosis activities). The answer options will use a 5-point Likert scale indicating low (1) to high (5) readiness/potential.

The questions regarding potential also help indicate the extent to which companies have information/knowledge of other companies at their location/industrial park. A screenshot of example questions in this section is provided in the Appendix (see Fig. 5).

\section{3) Informational Aspects - Availability and Sharing}

The extent of information-related barriers is reflected in concept awareness, internal and public availability of information and knowledge, and willingness to disclose the latter.

First, the company's policies and practices in terms of internal and external exchange of knowledge are examined. 'Policy' refers to management support for facilitating knowledge sharing, while 'practice' refers to existing formal and informal communication channels and methods of knowledge sharing. Companies could benefit from improving or qualifying existing channels and practices, instead of developing and imposing new ones. An example question on communication channels is given in Fig. 2, and a screenshot of this question is provided in the Appendix (see Fig. 6).

\begin{tabular}{|c|c|c|c|c|c|}
\hline $\begin{array}{l}\text { Which commu } \\
\text { to exchange } \\
\text { partners? }\end{array}$ & $\begin{array}{l}\text { on ch } \\
\text { ience }\end{array}$ & $\begin{array}{l}\text { inels do } \\
\text { and } \mathrm{k} \mathbf{I}\end{array}$ & $\begin{array}{l}\text { mainly us } \\
\text { ledge wit }\end{array}$ & $\begin{array}{r}\text { in yo } \\
\text { coll }\end{array}$ & $\begin{array}{l}\text { company } \\
\text { ues and }\end{array}$ \\
\hline & & & in your com & any & \\
\hline & Never & Rarely & Sometimes & Often & Always \\
\hline & 1 & 2 & 3 & 4 & 5 \\
\hline $\begin{array}{l}\text { Face-to-face } \\
\text { communication }\end{array}$ & $\square$ & $\square$ & $\square$ & $\square$ & $\square$ \\
\hline $\begin{array}{l}\text { Virtual face-to- } \\
\text { face } \\
\text { communication }\end{array}$ & $\square$ & $\square$ & $\square$ & $\square$ & $\square$ \\
\hline E-mail & $\square$ & $\square$ & $\square$ & $\square$ & $\square$ \\
\hline Intranet & $\square$ & $\square$ & $\square$ & $\square$ & $\square$ \\
\hline Expert systems & $\square$ & $\square$ & $\square$ & $\square$ & $\square$ \\
\hline
\end{tabular}

Fig. 2 Example Survey Question - Knowledge Sharing
Second, the availability of needed information is investigated. To this end, we will ask whether certain information about inputs and outputs is known within the company, whether it is already published/publicly available (e.g., in environmental reports), and whether it is generally subject to confidentiality. The types of information to be addressed are listed in Table II. This information is typically used to identify synergies, but at a high level of detail [35]. In order to examine the willingness to share information, we will include questions on the relevance of the types of information, as well as questions on the disclosure of information and its level of detail. An example question concerning information confidentiality is given in Fig. 3, and a screenshot of this question is provided in the Appendix (see Fig. 7).

TABLE II.

NECESSARY INFORMATION FOR INDUSTRIAL SYMBIOSIS

\begin{tabular}{|l|l|}
\hline Information type & Examples/Level of detail \\
\hline Resource type & Material, energy, water, EWC classification \\
\hline Resource quantity & Average per year/per month/per day/per hour \\
\hline Supply pattern & Constant/fluctuating, maximum/minimum, lot size \\
\hline Resource property & Components/ingredients, pollution, temperature \\
\hline Resource source & $\begin{array}{l}\text { Plant type (e.g., processing/production plant), } \\
\text { utilization (e.g., material input, drying, air } \\
\text { conditioning, process heat), specific plant (e.g., } \\
\text { industrial furnace) }\end{array}$ \\
\hline Availability period & $\begin{array}{l}\text { All year/seasonal, month details (e.g., April- } \\
\text { August), date specification (e.g., 01.04.19- } \\
04.12 .20), \text { shift system (e.g., Mo-Fr 5:30 to 22:30) }\end{array}$ \\
\hline Supplier/customer & Type, name \\
\hline Price/cost & Total per year/per unit, upper/lower price limit \\
\hline
\end{tabular}

Are the following types of information classified as confidential in your company and therefore subject to disclosure restrictions to other companies (e.g., non-disclosure agreements)?

\begin{tabular}{lccc} 
& \multicolumn{3}{c}{ Raw materials } \\
Resource type & Yes & Uncertain & No \\
Resource quantity & $\square$ & $\square$ & $\square$ \\
Supply pattern & $\square$ & $\square$ & $\square$ \\
Resource properties & $\square$ & $\square$ & $\square$ \\
Availability period & $\square$ & $\square$ & $\square$ \\
Supplier/customer & $\square$ & $\square$ & $\square$ \\
Price/cost & $\square$ & $\square$ & $\square$ \\
& $\square$ & $\square$ & $\square$ \\
\hline
\end{tabular}

Fig. 3 Example Survey Question - Information Sharing

Another important aspect related to information sharing is the type of information exchange:

- Direct: Other interested companies in the industrial park can receive or view information.

- Indirect: An intermediary receives the information, processes and analyzes it, and passes on the results of the analysis (e.g., that a synergy potential is presumed or not) to other companies, without the latter having access to the original information 
Companies' preference for one type or the other can provide important insight into a suitable mechanism for information exchange in an industrial park and for the design of appropriate ICT support.

\section{4) ICT Support-Awareness and Design}

In this section of the questionnaire, the awareness of ICT tools and the perception their usefulness are addressed on the basis of provided functions.

Based on [9], different types of ICT tools (e.g., online waste market, synergy identification system) will be presented with examples, in order to assess participants' awareness of them. Subsequently, selected functions of these tools (e.g., exchange market, matching engine, social applications) will be presented, in order to examine whether these functions are considered useful and/or would be used. At this point, a question is included inquiring whether a direct or indirect exchange of information is preferred. The questionnaire for both the companies in industrial parks and the park management should include a question of who should provide and operate such a tool (see Fig. 4).

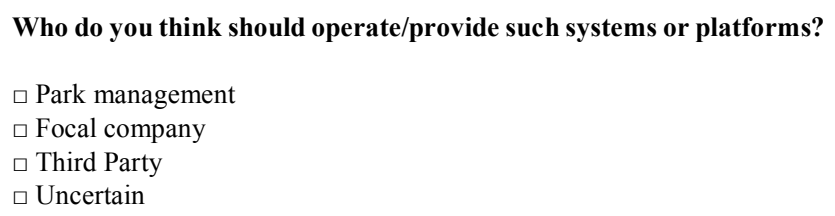

Fig. 4 Example Survey Question - ICT

Since the questionnaire will be tailored to two different target groups (companies in industrial parks and park management), some questions will vary slightly according to the role of the participants, and some will only be accessible to one target group or another. While the companies in industrial parks will assess their own readiness for industrial symbiosis and their information level, the park managers will assess the readiness and the information levels of the companies located in their park, as well as their willingness to act as facilitator in coordinating industrial symbiosis activities or providing services.

\section{Discussion AND FutURE STEPS}

In the existing industrial symbiosis research, managerial and informational issues and associated ICT support are not sufficiently addressed. In particular, empirical research capturing industrials actors' perceptions of these barriers and ICT is lacking. In order to develop an appropriate ICT tool to overcome the barriers (the aim of our long-term research), it is necessary to identify the specific underlying problems, needs, and resistances/aversions of the potential users.

Our first discussions with industrial park members and managers have shown that a general interest and a willingness to cooperate are present, but the human, time, and financial resources necessary to pursue and adequately implement the concept are rarely made available in the companies. These conversations also revealed that the awareness of the concept of industrial symbiosis is not perceived as an issue; however, the exchange of information was always seen as problematic and in need of improvement. Furthermore, none of the discussion partners knew of existing ICT tools, but they imagined that using them would be beneficial. These findings confirm, contradict, and complement the statements made in previous studies mentioned in Section I and II.

Since implementing industrial symbiosis is highly contextdependent, small samples are not representative of a holistic understanding of the relevance of managerial and informational problems. Therefore, in order to reach as many actors as possible and to get a deeper and more holistic picture of these issues, we designed an online questionnaire targeting the relevant players of industrial symbiosis in industrial parks. By conducting the online questionnaire as the next step in our long-term research project, we aim to expand understanding of the problems/barriers that we have identified in the existing literature on industrial symbiosis, as discussed in Section II.

At this point in our research, the responses to the questionnaire are particularly important in providing guidance on how to design and use applicable ICT support in industrial parks and how to coordinate industrial symbiosis activities (e.g., information flow). After the results of the questionnaire have been obtained, the next steps in our research project will involve discussing the related issues in more detail with companies in industrial parks and with park management, using qualitative approaches such as interviews and focus group discussions. After that, we will use the results from both the questionnaire and the qualitative methods to develop an adequate, appropriate concept for an ICT support tool for industrial symbiosis for industrial parks, along with an instantiation of the tool. For the final step in our long-term research, the developed tool will be evaluated by companies in industrial parks and by park management, again using a questionnaire. 
APPENDIX

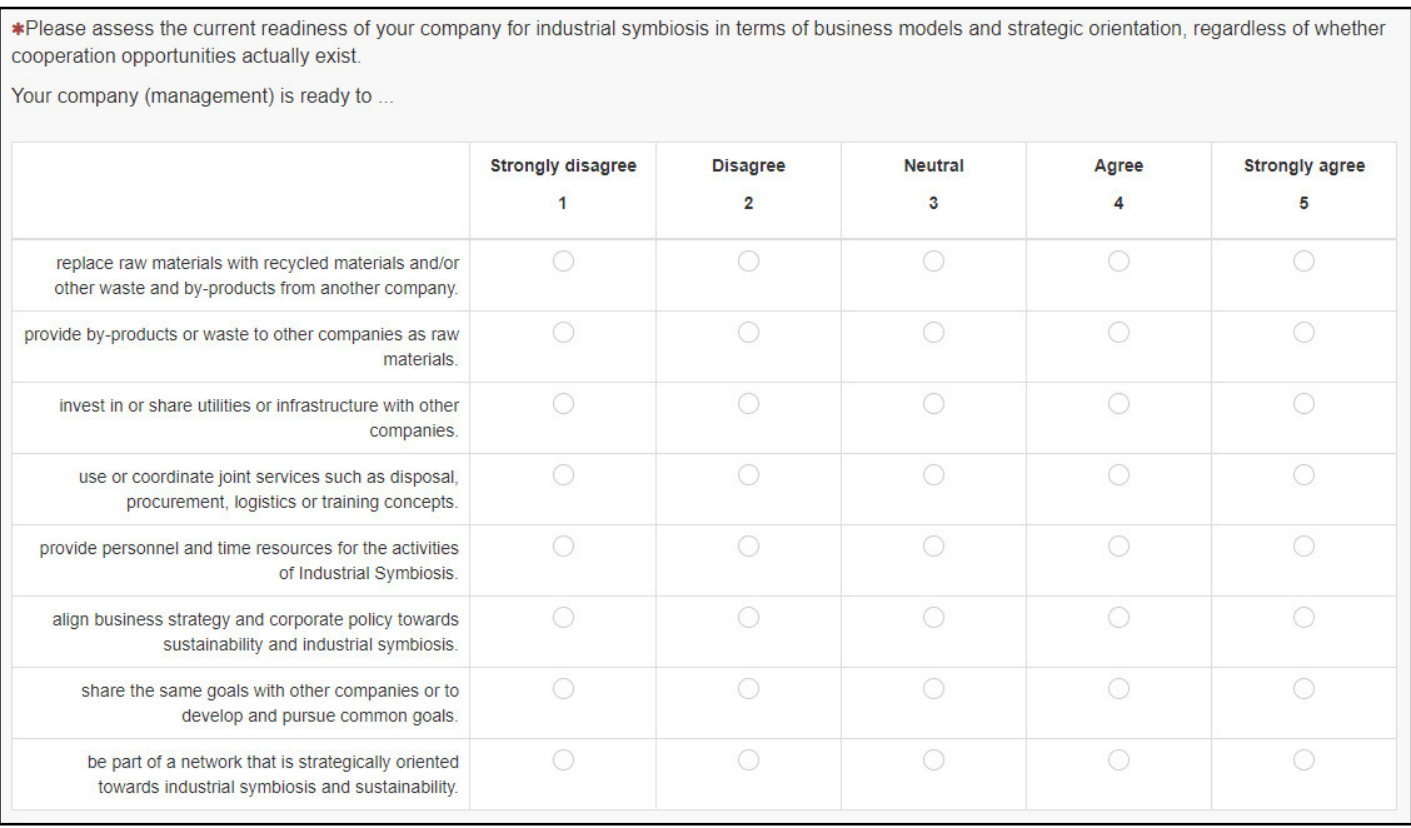

Fig. 5 Screenshot: Example Survey Question - Readiness

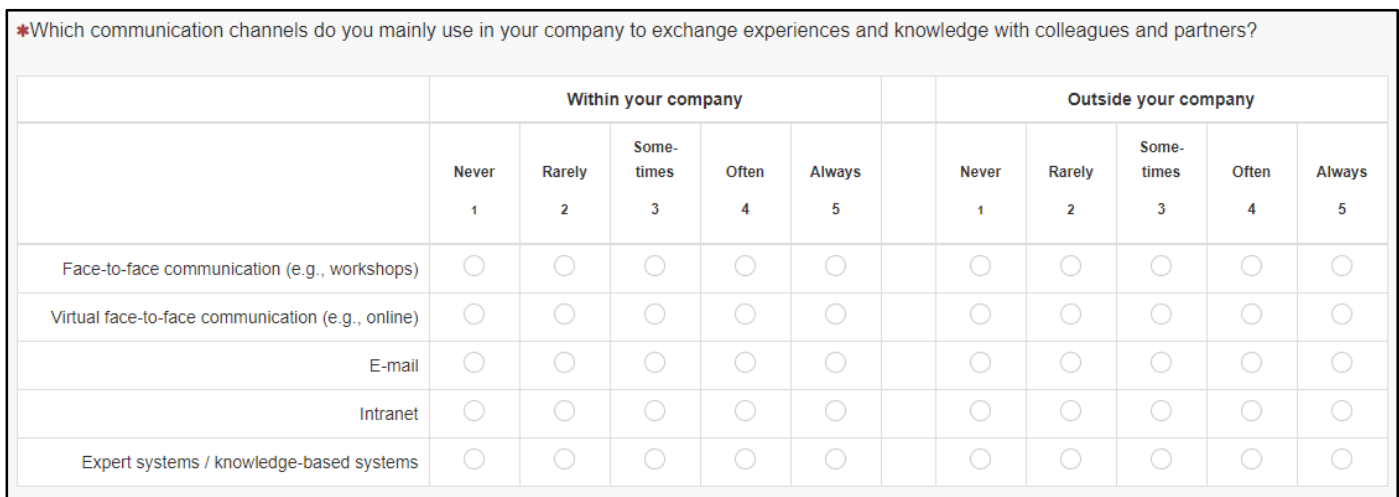

Fig. 6 Screenshot: Example Survey Question - Knowledge Sharing

*Are the following types of information classified as confidential in your company and therefore subject to disclosure restrictions to other companies (e.g., non-disclosure agreements)?

\begin{tabular}{|c|c|c|c|c|c|c|}
\hline & \multicolumn{3}{|c|}{ Raw materials } & \multicolumn{3}{|c|}{ Waste and by-products } \\
\hline & Yes & Uncertain & No & Yes & Uncertain & No \\
\hline Resource type & & & & & & \\
\hline Resource quantity & 0 & & & & & \\
\hline Supply pattern & & & 0 & & & \\
\hline Resource properties & & & & & & \\
\hline Resource source & & & & & & O \\
\hline Availability period & & & & & & \\
\hline Supplier/customer & & & & & & \\
\hline Price/cost & & & & & & \\
\hline
\end{tabular}

Fig. 7 Screenshot: Example Survey Question - Information Sharing 


\section{REFERENCES}

[1] M. R. Chertow, "Industrial symbiosis: Literature and Taxonomy," Annual Review of Energy and the Environment, vol. 25, no. 1, pp. 313337 , Nov. 2000

[2] D. R. Lombardi and P. Laybourn, "Redefining Industrial Symbiosis," JIE, vol. 16, no. 1, pp. 28-37, Feb. 2012.

[3] E. A. Lowe and L. K. Evans, "Industrial ecology and industrial ecosystems," Journal of Cleaner Production, vol. 3, no. 1-2, pp. 4753, Jan. 1995.

[4] H.-S. Park, E. R. Rene, S.-M. Choi, and A. S. F. Chiu, "Strategies for sustainable development of industrial park in Ulsan, South KoreaFrom spontaneous evolution to systematic expansion of industrial symbiosis," Journal of Environmental Management, vol. 87, no. 1, pp 1-13, Apr. 2008

[5] D. Sakr, L. Baas, S. El-Haggar, and D. Huisingh, "Critical success and limiting factors for eco-industrial parks: global trends and Egyptian context," Journal of Cleaner Production, vol. 19, no. 11, pp. 11581169, Jul. 2011.

[6] A. Golev, G. D. Corder, and D. P. Giurco, "Barriers to Industrial Symbiosis: Insights from the Use of a Maturity Grid," Journal of Industrial Ecology, vol. 19, no. 1, pp. 141-153, Feb. 2015.

[7] R. Lombardi, "Non-technical barriers to (and drivers for) the circular economy through industrial symbiosis: A practical input," Economics And Policy Of Energy And The Environment, Feb. 2017.

[8] G. B. Grant, T. P. Seager, G. Massard, and L. Nies, "Information and Communication Technology for Industrial Symbiosis," JIE, vol. 14, no. 5 , pp. 740-753, Oct. 2010.

[9] G. van Capelleveen, C. Amrit, and D. M. Yazan, "A Literature Survey of Information Systems Facilitating the Identification of Industrial Symbiosis," in From Science to Society, P. Hitzelberger, S. Naumann, V. Wohlgemuth, and B. Otjacques, Eds. Springer, Cham, 2018, pp. $155-169$.

[10] A. Maqbool, F. Mendez Alva, and G. Van Eetvelde, "An Assessment of European Information Technology Tools to Support Industrial Symbiosis," Sustainability, vol. 11, no. 1, p. 131, Dec. 2018

[11] D. Gibbs and P. Deutz, "Reflections on implementing industrial ecology through eco-industrial park development," Journal of Cleaner Production, vol. 15, no. 17, pp. 1683-1695, Nov. 2007.

[12] E. Susur, A. Hidalgo, and D. Chiaroni, "A strategic niche management perspective on transitions to eco-industrial park development: A systematic review of case studies," Resources, Conservation and Recycling, vol. 140, pp. 338-359, Jan. 2019.

[13] M. Chertow and J. Park, "Scholarship and Practice in Industrial Symbiosis: 1989-2014," in Taking Stock of Industrial Ecology, Springer, Cham, 2016, pp. 87-116.

[14] S. Menato, S. Carimati, E. Montini, P. Innocenti, L. Canetta, and M. Sorlini, "Challenges for the adoption of industrial symbiosis approaches within industrial agglomerations," in 2017 International Conference on Engineering, Technology and Innovation (ICE/ITMC), Funchal, 2017, pp. 1293-1299.

[15] I. Siskos and L. N. V. Wassenhove, "Synergy Management Services Companies: A New Business Model for Industrial Park Operators," Journal of Industrial Ecology, vol. 21, no. 4, pp. 802-814, Aug. 2017.

[16] L. R. Bacudio et al., "Analyzing barriers to implementing industrial symbiosis networks using DEMATEL," Sustainable Production and Consumption, vol. 7, pp. 57-65, Jul. 2016.

[17] M. A. B. Promentilla et al., "Problematique approach to analyse barriers in implementing industrial ecology in philippine industrial parks," Chemical Engineering Transactions, vol. 52, pp. 811-816, 2016.
[18] D. Ceglia, M. C. S. de Abreu, and J. C. L. Da Silva Filho, "Critical elements for eco-retrofitting a conventional industrial park: Social barriers to be overcome," Journal of Environmental Management, vol. 187, pp. 375-383, Feb. 2017.

[19] U. Fric and B. Rončević, "E-Simbioza - Leading the Way to a Circular Economy through Industrial Symbiosis in Slovenia," SocEkol, vol. 27, no. 2, pp. 119-140, 2018.

[20] M. Kurdve, C. Jönsson, and A.-S. Granzell, "Development of the urban and industrial symbiosis in western Mälardalen," in Procedia CIRP, 2018, vol. 73, pp. 96-101.

[21] M. Ormazabal, V. Prieto-Sandoval, R. Puga-Leal, and C. Jaca, "Circular Economy in Spanish SMEs: Challenges and opportunities," Journal of Cleaner Production, vol. 185, pp. 157-167, Jun. 2018.

[22] T. Domenech, R. Bleischwitz, A. Doranova, D. Panayotopoulos, and L. Roman, "Mapping Industrial Symbiosis Development in Europe typologies of networks, characteristics, performance and contribution to the Circular Economy," Resources, Conservation and Recycling, vol. 141, pp. 76-98, Feb. 2019.

[23] L. Kosmol, "Sharing is Caring - Information and Knowledge in Industrial Symbiosis: A Systematic Review," presented at the Conference on Business Informatics, Moscow, Russia, 2019.

[24] M. R. Chertow, “Uncovering' industrial symbiosis,” JIE, vol. 11, no. 1, pp. 11-30, 2007.

[25] G. Massard and S. Erkman, "A regional Industrial Symbiosis methodology and its implementation in Geneva, Switzerland," 2007.

[26] L. Fraccascia, M. Mango, and V. Albino, "Business models for industrial symbiosis: a guide for firms," in Procedia Environmental Science, Engineering and Management, Italy, 2016, vol. 3, pp. 83-93.

[27] F. Boons, W. Spekkink, and Y. Mouzakitis, "The dynamics of industrial symbiosis: a proposal for a conceptual framework based upon a comprehensive literature review," JCP, vol. 19, no. 9-10, pp. 905$911,2011$.

[28] M. R. Ghali, J.-M. Frayret, and J.-M. Robert, "Green social networking: Concept and potential applications to initiate industrial synergies," Journal of Cleaner Production, vol. 115, pp. 23-35, 2016.

[29] L. Fraccascia and D. M. Yazan, "The role of online information-sharing platforms on the performance of industrial symbiosis networks," Resources, Conservation and Recycling, vol. 136, pp. 473-485, 2018.

[30] L. Kosmol and W. Esswein, "Capturing the Complexity of Industrial Symbiosis," in Advances and New Trends in Environmental Informatics, H.-J. Bungartz, D. Kranzlmüller, V. Weinberg, J. Weismüller, and V. Wohlgemuth, Eds. Springer International Publishing, 2018, pp. 183-197.

[31] M. Benedict, L. Kosmol, and W. Esswein, "Designing Industrial Symbiosis Platforms - from Platform Ecosystems to Industrial Ecosystems," in PACIS 2018, Yokohama, Japan, 2018, pp. 26-30.

[32] F. A. Halstenberg, K. Lindow, and R. Stark, "Utilization of Product Lifecycle Data from PLM Systems in Platforms for Industrial Symbiosis," Procedia Manufacturing, vol. 8, pp. 369-376, Jan. 2017.

[33] K. Peffers, T. Tuunanen, M. A. Rothenberger, and S. Chatterjee, "A Design Science Research Methodology for Information Systems

[34] Research," Journal of Management Information Systems, vol. 24, no. 3, pp. $45-77$, Dec. 2007

[35] D. C. A. Pigosso, A. Schmiegelow, and M. M. Andersen, "Measuring the Readiness of SMEs for Eco-Innovation and Industrial Symbiosis: Development of a Screening Tool," Sustainability, vol. 10, no. 8, p. 2861 , Aug. 2018

[36] F. Cecelja et al., "e-Symbiosis: technology-enabled support for Industrial Symbiosis targeting Small and Medium Enterprises and innovation,” Journal of Cleaner Production, vol. 98, pp. 336-352, Jul. 2015. 